\title{
Correlation between vascular inflammation markers, diastolic dysfunction and cardiovascular risk in patients with Takayasu arteritis
}

\begin{abstract}
Sebastiano Cicco $^{1, *}$, Vanessa Desantis ${ }^{1,2,}{ }^{*}$, Antonio Vacca3, Gerardo Cazzato ${ }^{4}$, Antonio G. Solimando ${ }^{1}$, Anna Cirulli ${ }^{1}$, Silvia Noviello ${ }^{1}$, Cecilia Susca ${ }^{5}$, Marcella Prete ${ }^{1}$, Gabriele Brosolo ${ }^{3}$, Cristiana Catena ${ }^{3}$, Aurelia Lamanuzzi ${ }^{1}$, Ilaria Saltarella ${ }^{1}$, Maria Antonia Frassanito ${ }^{6}$, Antonella Cimmino ${ }^{4}$, Giuseppe Ingravallo ${ }^{4}$, Leonardo Resta ${ }^{4}$, Roberto Ria ${ }^{1,+}$ and Monica Montagnani ${ }^{2,+}$

${ }^{1}$ Department of Biomedical Sciences and Human Oncology (DIMO), Unit of Internal Medicine and Clinical Oncology, University of Bari Aldo Moro Medical School, Bari, Italy (sebastiano.cicco@uniba.it; vanessa.desantis@uniba.it; antonio.solimando@uniba.it; alisaciru@gmail.com; silvia.noviello88@gmail.com; marcella.prete@uniba.it; aurelia.lamanuzzi@uniba.it; ilaria.saltarella@uniba.it; roberto.ria@uniba.it)
\end{abstract}

${ }^{2}$ Department of Biomedical Sciences and Human Oncology, Pharmacology Section, Medical School, University of Bari Aldo Moro, Bari, Italy (vanessa.desantis@uniba.it; monica.montagnani@uniba.it)

${ }^{3}$ Division of Internal Medicine, Department of Medicine, Building 8, University of Udine, I-33100 Udine (UD), Italy (antonio.vacca94@gmail.com; gabriele.brosolo@uniud.it; cristiana.catena@uniud.it)

4Section of Pathology, Department of Emergency and Organ Transplantation (DETO), University of Bari "Aldo Moro", 70124, Bari, Italy (gerycazzato@hotmail.it; micasucci@inwind.it; giuseppe.ingravallo@uniba.it; leonardo.resta@uniba.it)

5Department of Admission and Emergency Medicine and Surgery "S. Maria degli Angeli" hospital, ASL Bari, Putignano (BA), Italy (ceciliasusca@libero.it)

6Department of Biomedical Sciences and Human Oncology (DIMO), General Pathology Unit, University of Bari Medical School, Bari, Italy (antofrassanito@gmail.com).

*These authors contributed equally to this work.

tThese authors contributed equally to this work as senior authors.

\section{Correspondence:}

Roberto Ria, MD.

Department of Biomedical Sciences and Human Oncology (DIMO), U.O.C. Medicina Interna "Guido Baccelli" University of Bari Aldo Moro - Policlinico di Bari, Piazza Giulio Cesare 11, I-70124 BARI (Italy). Phone +39-080-5478057; Fax+39-080-5592189; e-mail roberto.ria@uniba.it. 


\begin{abstract}
Background: Takayasu Arteritis (TAK) increases vascular stiffness and arterial resistance. Hypertension and atherosclerosis lead to similar changes. We investigated possible differences in cardiovascular remodeling between these diseases and whether the differences are correlated with immune cell expression.

Methods: Patients with active TAK arteritis were compared with age- and sex-matched hypertensive and atherosclerotic patients. In a subpopulation of TAK patients, Treg/Th17 cells were measured before (T0) and after 18 months (T18) of infliximab treatment. Echocardiogram, supraaortic Doppler ultrasound, and lymphocytogram were performed in all patients. Histological and immunohistochemical evaluation of the vessel wall was performed to compare the in vivo results.

Results: TAK patients have increased aortic valve dysfunction and diastolic dysfunction. These data have been associated with uric acid levels. A significant increase in aortic stiffness was also noted and associated with peripheral T lymphocyte levels. $\mathrm{CD}^{+}{ }^{+} \mathrm{CD} 4^{+}$cell infiltrates were detected in the vessel wall samples of these patients. They had a lower mean percentage of Tregs at T0 than controls, but levels increased significantly at T18. Opposite results were found in Th17 cells. Finally, TAK patients were found to have an increased risk of atherosclerotic cardiovascular disease (ASCVD).

Conclusion: Our data suggest that different pathogenic mechanisms of vessel damage, including atherosclerosis, underlie TAK patients compared with control subjects. The increased risk of ASCVD in TAK patients correlates directly with the degree of inflammatory cell infiltration in the vessel wall. Infliximab restores the normal frequency of Tregs/Th17 in TAK patients and allows a possible reduction of steroids and immunosuppressants.
\end{abstract}

Keywords: Takayasu arteritis; echocardiography; immune cell infiltration; vascular stiffness; T helper like cells; regulatory T lymphocytes. 


\section{Introduction}

Vasculitis of large vessels are diseases in which inflammation predominantly affects the wall of large and medium-sized arteries, including the aorta and its main branches and the pulmonary artery [1]. The clinical signs and symptoms are due to both systemic inflammation and local vascular complications and are associated with elevated inflammatory markers [1]. Among these diseases, Takayasu arteritis (TAK) is a chronic granulomatous vasculitis. Although the insidious and nonspecific early clinical symptoms may cause this vasculitis to be often overlooked until its later stages, in other cases all symptoms are synchronous and disease progression faster. The majority of TAK patients present with concurrent nonspecific inflammatory signs and symptoms, primarily associated with local stenosis (93\%), occlusion (57\%), dilatation (16\%), and aneurysm formation (7\%) [2].

Abnormal immune response is a crucial factor in the pathogenesis of TAK. Regulatory T lymphocytes (Treg lymphocytes), a subset of $C D 4^{+} T$ cells that express high levels of both CD25 (the $\alpha$-chain of the high-affinity interleukin-2 receptor) and the transcription factor forkhead box protein P3 (Foxp3), are central mediators of peripheral tolerance [3]. Under certain conditions, Treg cells can differentiate into T helper (Th)-like cells, leading to a drastic change in their immune function. Indeed, recent evidence suggests that Treg cells can differentiate into Th1, Th2 or Th17 cells, leading to a shift from an immunosuppressive function to a role in the pathogenesis of autoimmune diseases [4]. The potential role of Treg cells and their associated cytokine secretion in TAK patients is under active investigation to expand the horizon for more effective therapies.

Because of the inflammatory nature of TAK disease, first-line treatment generally consists of high-dose steroids (usually prednisone). Commonly prescribed second-line agents include immunosuppressants [2]. Although these traditional agents can be effective in inducing remission of TAK, relapses remain common when prednisone is discontinued $[5,6]$. Recent advances in the treatment of TAK patients have been based on the increased understanding of the pathophysiology of TAK and the concurrent availability of new biologic therapies [7]. To date, the administration of anti-tumor necrosis factor-alpha (TNF- $\alpha$ ) agents, such as infliximab, appears to be a valuable and safe alternative to standard therapy [4]. By blocking TNF- $\alpha$-induced activation of inflammatory signals, infliximab leads to long-term clinical improvement with significant benefits for patients' quality of life $[8,9]$.

TAK patients are likely to have lesions at different vascular levels, mostly at the subclavian and carotid levels, with either bilateral involvement or focal involvement confined to one carotid or subclavian artery, which can be monitored by ultrasonography $[10,11]$. At the onset, pathophysiological features are usually nonspecific and include systemic disturbances such as fever, anorexia, weight loss, night sweats, and fatigue. As the disease progresses, diffuse proliferation of the arterial tunica intima along with fibrotic and stenotic lesions may cause ischemic symptoms, whose clinical manifestations depend on the location of the affected arteries. Further progression of TAK leads to destruction of the tunica media, which is often accompanied by aortic regurgitation as well as aneurysm and vessel rupture [12].

Few data are available on ultrasound-based assessment of cardiac function in large vessel vasculitis, although features of early cardiac involvement have been described in other autoimmune diseases [13,14]. Nevertheless, an increase in left ventricular mass [15] and indirect involvement of the right ventricle, secondary to pulmonary hypertension, have been detected by echocardiography in TAK patients [16]. Thus, as with several other diseases associated with inflammatory features in the arterial wall, such as hypertension and atherosclerosis $[17,18]$ and oxidative stress $[18,19]$, changes in cardiac structure and function may characterize the progression of TAK disease, increasing the overall risk of cardiovascular morbidity/mortality $[20,21]$. However, ultrasonographic parameters that can accurately characterize cardiovascular 
risk and correlations between inflammatory parameters and cardiovascular structural changes have not been studied in TAK patients.

Cardiovascular risk data are based on the assessment of vascular changes [22]. The increased vascular resistance is the consequence of many phenomena associated with the development of atherosclerosis [22]. The cornerstone of this evolution is inflammation, which is due to increased infiltration of immune cells into the vessel wall [22-24]. Therefore, an inflammatory state may also be characteristic of more classic cardiovascular diseases such as hypertension and atherosclerosis. Both conditions have been shown to play a role in cardiac and vessel remodeling, leading to an increased risk of mortality [25]. Moreover, in classic cardiovascular diseases, there are accepted parameters for assessing organ damage, which represents the referring value also in ultrasound assessment [25]. The aim of this study was to compare vascular and cardiac ultrasonography parameters predictive of increased cardiovascular risk in TAK patients, with those obtained in hypertensive and atherosclerotic patients. We also investigated the relationship between cardiac and carotid artery changes (also using ultrasonography) and peripheral blood inflammatory cell concentrations. In addition, we investigated new markers (proportion of Treg and Th17 cells) in TAK-refractory patients treated with infliximab and found clinical improvement compared to hypertensive and atherosclerotic patients.

\section{Results}

\section{Baseline features and clinical differences}

Baseline history information and clinical parameters for all patients are summarized in Table 1 and Table 2. While no significant difference was found in the incidence of overweight/obesity (Table $1)$, body mass index (BMI) $(25.21 \pm 5.21 / 28.44 \pm 4.22)$ and body surface area (BSA) (1.73 \pm $0.29 / 1.89 \pm 0.23$ ) values were lower in TAK patients than in hypertensive and atherosclerotic patients (control group). Total cholesterol (171.04 $\pm 43.66 / 192.01 \pm 32.83$ ) and low-density lipoprotein (LDL) cholesterol $(96.36 \pm 34.03 / 113.82 \pm 29.34)$ were slightly albeit significantly lower in the TAK group, while the values for high-density lipoprotein (HDL) $(55.96 \pm 23.39 / 56.63 \pm 11.24)$ or triglycerides $(103.90 \pm 37.95 / 107.91 \pm 42.56)$ overlapped between the groups (Table 2$)$. Accordingly, the estimated incidence of atherosclerosis was low in our TAK patients and treatment with statins was less frequent than in the control patients (Table 1).

\section{Table 1. Baseline history information of enrolled patients.}

\begin{tabular}{cccc}
\hline Characteristic & Takayasu Arteritis & Arterial Hypertension & p Value \\
\hline Age (years) & $49.27 \pm 18.87$ & $51.43 \pm 12.51$ & $\mathrm{Ns}$ \\
F/M & $22 / 8$ & $22 / 8$ & $\mathrm{Ns}$ \\
BMI $\left(\mathrm{kg} / \mathrm{m}^{2}\right)$ & $25.21 \pm 5.21$ & $28.44 \pm 4.22$ & $0.02 \#$ \\
BSA $\left(\mathrm{m}^{2}\right)$ & $1.73 \pm 0.29$ & $1.89 \pm 0.23$ & $0.04 \#$ \\
Overweight/Obesity $\left(\mathrm{n}^{\circ}\right)$ & $9 / 5$ & $12 / 7$ & $\mathrm{Ns}$ \\
Arterial hypertension $\left(\mathrm{n}^{\circ}\right)$ & 12 & 30 & 0.001 \\
Diabetes $\left(\mathrm{n}^{\circ}\right)$ & 3 & 4 & $\mathrm{Ns}$ \\
Atherosclerosis $\left(\mathrm{n}^{\circ}\right)$ & 3 & 30 & 0.001
\end{tabular}




\begin{tabular}{|c|c|c|c|}
\hline Ischemic heart disease $\left(n^{\circ}\right)$ & 4 & 3 & Ns \\
\hline Ischemic brain disease $\left(n^{\circ}\right)$ & 3 & 2 & Ns \\
\hline Preserved EF Heart Failure $\left(n^{\circ}\right)$ & 3 & 5 & Ns \\
\hline Smoke $\left(n^{\circ}\right)$ & 5 & 7 & Ns \\
\hline Cigarettes (n/day) [IQR] & $15[7.5-18]$ & $13[7-20]$ & Ns \\
\hline ASCVD-10-yr (\%) & $21.69 \pm 16.09$ & $8.55 \pm 7.63$ & 0.001 \\
\hline \multicolumn{4}{|l|}{ Medications } \\
\hline Anti-hypertensives drugs $\left(n^{\circ}\right)$ & 12 & 30 & 0.001 \\
\hline Antiplatelet $\left(n^{\circ}\right)$ & 11 & 10 & Ns \\
\hline Statins $\left(n^{\circ}\right)$ & 3 & 25 & 0.001 \\
\hline Oral Antidiabetic drugs $\left(n^{\circ}\right)$ & 3 & 3 & Ns \\
\hline Insulin $\left(n^{\circ}\right)$ & 1 & 1 & Ns \\
\hline Steroids $\left(n^{\circ}\right)$ & 22 & - & \\
\hline Prednisone equivalent (mg/day) & $27.36 \pm 17.86$ & - & \\
\hline DMARDs $\left(n^{\circ}\right)$ & 22 & - & \\
\hline Infliximab $\left(n^{\circ}\right)$ & 16 & - & \\
\hline
\end{tabular}

$\mathrm{ASCVD}=$ atherosclerotic cardiovascular disease; $\mathrm{BMI}=$ Body Mass Index; $\mathrm{BSA}=$ Body surface area; DMARDS= Disease modified anti rheumatic drugs. EF= Ejection Fraction Chi-squared test; \# for Student T-test for unpaired samples; \#\# for Mann-Whitney test

Table 2. Clinical and routine parameters of enrolled patients.

\begin{tabular}{cccc}
\hline Parameter & Takayasu Arteritis & Arterial Hypertension & p Value \\
\hline SBP $(\mathrm{mmHg})$ right & $125.30 \pm 20.34$ & $123.35 \pm 10.27$ & Ns \\
SBP $(\mathrm{mmHg})$ left & $120.65 \pm 30.31$ & $125.11 \pm 9.32$ & Ns \\
DBP $(\mathrm{mmHg})$ right & $70.71 \pm 2.495$ & $78.93 \pm 6.10$ & 0.0004 \\
DBP $(\mathrm{mmHg})$ left & $72.35 \pm 8.00$ & $79.73 \pm 5.01$ & 0.0002 \\
HR $(\mathrm{bpm})$ & $76.28 \pm 13.99$ & $67.80 \pm 8.57$ & 0.0076 \\
Creatinine $(\mathrm{mg} / \mathrm{dl})$ & $0.92 \pm 0.44$ & $0.81 \pm 0.21$ & $\mathrm{Ns}$ \\
Creatinine Clearance $(\mathrm{ml} / \mathrm{min})$ & $89.93 \pm 34.32$ & $87.17 \pm 16.43$ & $\mathrm{Ns}$ \\
Glycaemia $(\mathrm{mg} / \mathrm{dl})$ & $98.82 \pm 32.16$ & $91.47 \pm 14.26$ & $\mathrm{Ns}$ \\
\hline
\end{tabular}




\begin{tabular}{cccc}
\hline Total Cholesterol $(\mathrm{mg} / \mathrm{dl})$ & $171.04 \pm 43.66$ & $192.01 \pm 32.83$ & 0.042 \\
HDL $(\mathrm{mg} / \mathrm{dl})$ & $55.96 \pm 23.39$ & $56.63 \pm 11.24$ & Ns \\
LDL $(\mathrm{mg} / \mathrm{dl})$ & $96.36 \pm 34.03$ & $113.82 \pm 29.34$ & 0.041 \\
Triglyceride $(\mathrm{mg} / \mathrm{dl})$ & $103.90 \pm 37.95$ & $107.91 \pm 42.56$ & $\mathrm{Ns}$ \\
Uric Acid $(\mathrm{mg} / \mathrm{dl})$ & $4.30 \pm 1.98$ & $4.65 \pm 1.19$ & $\mathrm{Ns}$ \\
\hline
\end{tabular}

SBP= Systolic Blood Pressure; DBP= Diastolic Blood Pressure; HR= heart rate; HDL= high-density lipoprotein; LDL= low-density lipoprotein.

Although the use of antihypertensive medications was less frequent in TAK patients (Table 1 ), no difference was observed in systolic blood pressure (SBP) values, either on the right arm $(125.30 \pm 20.3 / 4123.35 \pm 10.27)$ or on the left arm (120.65 $\pm 30.31 / 125.11 \pm 9.32)$ (Table 2). Instead, diastolic blood pressure (DBP) was significantly lower in both the right (70.71 \pm $2.495 / 78.93 \pm 6.10)$ and left arms (72.35 \pm 8.00/79.73 \pm 5.01$)$ in TAK patients than in controls (Table 2). Heart rate (HR) was significantly higher in TAK patients $(76.28 \pm 13.99 / 67.80 \pm 8.57)$ than controls (Table 2). Thus, there was no difference in individual cardiovascular risk factors between the two groups of enrolled patients.

\section{Ultrasound evaluation and vascular damage}

Interventricular septum (IVS) $(11.88 \pm 2.03 / 11.88 \pm 1.64)$ and left atrial volume (LAV) $(65.16 \pm$ $32.44 / 63.57 \pm 16.21$ ) were increased in patients with TAK, overlapping with values in hypertensive and atherosclerotic patients (Table 3). Also, left ventricular mass (LVM) $(205.30 \pm 63.11 / 205.91 \pm$ 44.73), LVM indexed for BSA (LVMi) $(118.70 \pm 32.20 / 117.04 \pm 21.89)$, and height 2.7 (LVMi2.7) $(56.07 \pm 19.25 / 58.37 \pm 12.01)$ were similar in both groups and always increased in hypertensive and atherosclerotic patients compared with the normal population [24,25]. Although most echocardiographic parameters were not significantly different between TAK and hypertensive and atherosclerotic patients (Table 3), TAK patients showed a trend to increase LAV indexed for BSA (LAVi) (37.42 $\pm 16.54 / 30.69 \pm 16.54$ ) (Table 3). These results suggest that TAK may have increased volume overload in the left heart, although both present similar cardiac remodeling.

Table 3. Echocardiografic parameters of enrolled patients.

\begin{tabular}{cccc}
\hline Parameter & Takayasu Arteritis & Arterial Hypertension & p Value \\
\hline IVS $(\mathrm{mm})$ & $11.88 \pm 2.03$ & $11.88 \pm 1.64$ & Ns \\
LvedD $(\mathrm{mm})$ & $47.02 \pm 5.76$ & $46.89 \pm 4.48$ & $\mathrm{Ns}$ \\
PWT $(\mathrm{mm})$ & $11.38 \pm 1.45$ & $11.44 \pm 1.25$ & $\mathrm{Ns}$ \\
LVedVol & $87.24 \pm 26.70$ & $77.69 \pm 15.62$ & Ns \\
LVM $(\mathrm{gr})$ & $205.30 \pm 63.11$ & $205.91 \pm 44.73$ & $\mathrm{Ns}$ \\
LVMi $\left(\mathrm{gr} / \mathrm{m}^{2}\right)$ & $118.70 \pm 32.20$ & $117.04 \pm 21.89$ & $\mathrm{Ns}$ \\
\hline
\end{tabular}




\begin{tabular}{|c|c|c|c|}
\hline LVMi2.7 & $56.07 \pm 19.25$ & $58.37 \pm 12.01$ & Ns \\
\hline Aod $(\mathrm{mm})$ & $32.71 \pm 4.56$ & $31.57 \pm 3.36$ & Ns \\
\hline Aoi $\left(\mathrm{mm} / \mathrm{m}^{2}\right)$ & $19.26 \pm 2.49$ & $17.24 \pm 2.15$ & Ns \\
\hline RWT & $0.48 \pm 0.08$ & $0.49 \pm 0.07$ & Ns \\
\hline $\mathrm{LAV}(\mathrm{mL})$ & $65.16 \pm 32.44$ & $63.57 \pm 16.21$ & Ns \\
\hline LAVi $\left(\mathrm{mL} / \mathrm{m}^{2}\right)$ & $37.42 \pm 16.54$ & $30.69 \pm 16.54$ & 0.01 \\
\hline Ejection Fraction (\%) & $61.42 \pm 5.41$ & $61.83 \pm 2.73$ & Ns \\
\hline E velocity $(\mathrm{cm} / \mathrm{s})$ & $69.44 \pm 16.45$ & $56.43 \pm 15.42$ & Ns \\
\hline A velocity $(\mathrm{cm} / \mathrm{s})$ & $65.63 \pm 26.40$ & $67.07 \pm 15.63$ & Ns \\
\hline $\mathrm{e}^{\prime}$ velocity $(\mathrm{cm} / \mathrm{s})$ & $8.20 \pm 0.51$ & $7.23 \pm 2.41$ & Ns \\
\hline E/e' ratio & $10.82 \pm 7.32$ & $9.10 \pm 2.89$ & Ns \\
\hline IMT (mm) & $1.93 \pm 0.79$ & $1.66 \pm 1.32$ & Ns \\
\hline Aortic wall thickness (mm) & $3.96 \pm 0.80$ & $2.83 \pm 0.57$ & 0.001 \\
\hline $\begin{array}{l}\text { Diastolic Dysfunction } \\
\text { (none/I/II/severe) }\end{array}$ & $9 / 10 / 9 / 2$ & $6 / 19 / 5 / 0$ & 0.049 \\
\hline $\begin{array}{l}\text { Aortic regurgitation severity } \\
\text { (none/mild-to-moderate/ } \\
\text { moderate-to-severe) }\end{array}$ & $17 / 8 / 5$ & $26 / 3 / 1$ & 0.033 \\
\hline
\end{tabular}

IVS= interventricular septum; LvedD= left ventricle end-diastolic diameter; $\mathrm{PWT}=$ posterior wall thickness; LVM= left ventricle mass; LVMi= LVM indexed for BSA; Aod= Aortic diameted; RWT=relative wall thickness; $L A V=$ left atrial volume; $L A V i=L A V$ indexed for $B S A ; I M T=$ intima-media thickness.

Increased diastolic dysfunction and aortic regurgitation were also observed in TAK patients (Table 3). Consistent with the evidence that diastolic dysfunction is associated with increased uric acid levels [26], a marker of endothelial stress, we found that uric acid levels were significantly elevated in TAK patients with severe aortic regurgitation compared with TAK patients without dysfunction $(5.06 \pm 1.51 / 2.96 \pm 0.79)$. Accordingly, TAK patients with moderate-severe aortic regurgitation had elevated uric acid levels compared with patients without regurgitation (6.03 \pm $1.22 / 3.64 \pm 1.21)$ or mild-to-moderate diastolic dysfunction $(6.03 \pm 1.22 / 3.18 \pm 1.20)$ (Figure $1 \mathrm{~A})$. Although uric acid levels were not significantly different between TAK and hypertensive patients $(4.30 \pm 1.98 / 4.65 \pm 1.19)$ (Table 2$)$, a correlation was observed between the severity of diastolic dysfunction and elevated uric acid levels in patients in the TAK group (Figure 1B). On the same line, the increase in arterial stiffness (ASI) $(16.54 \pm 7.88 / 13.28 \pm 3.11)$ observed in TAK patients compared with hypertensive and atherosclerotic patients (Figure 2A). Moreover, TAK patients without an already known cardiovascular disease showed a significant positive correlation with diastolic dysfunction (Figure 2B) and with uric acid levels (Figure $2 \mathrm{C}$ ). This may indicate that there is increased vessel remodeling in TAK. 


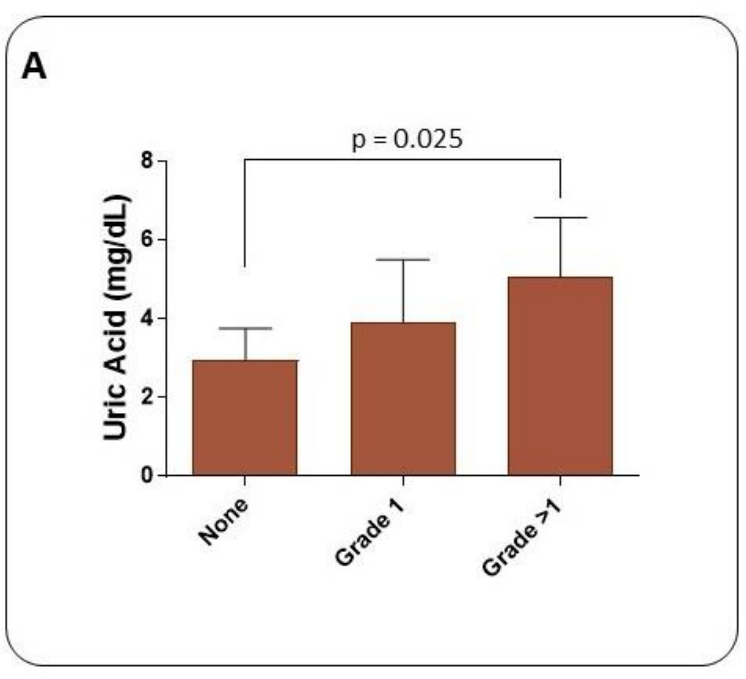

B

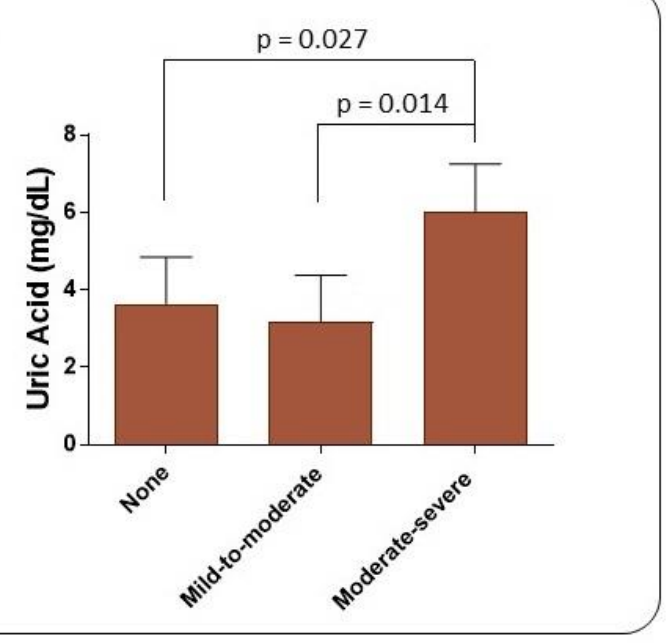

Figure 1: Uric acid levels in TAK patients increase according to the severity of heart diastolic dysfunction (A) and aortic valve regurgitation (B).
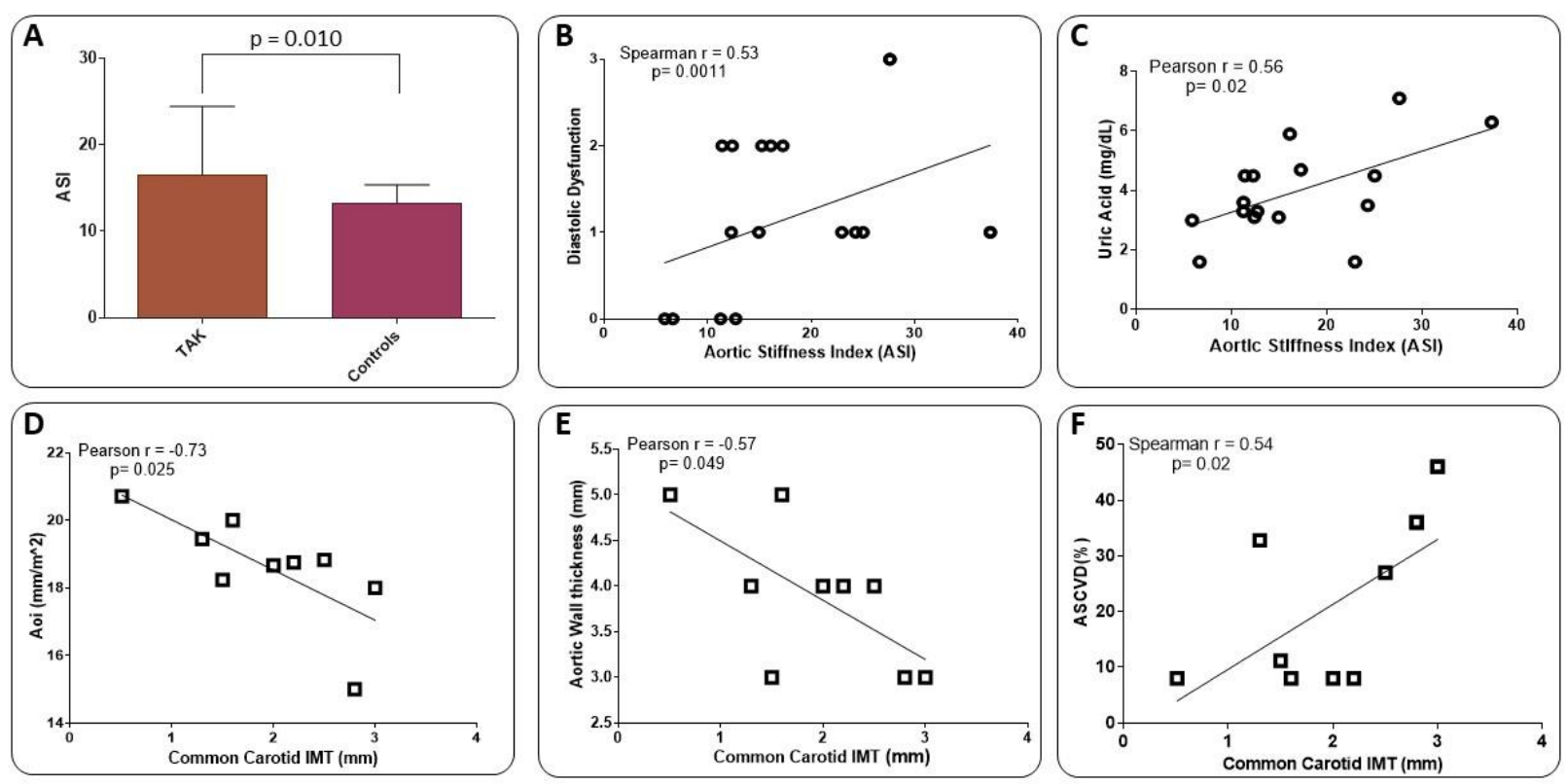

Figure 2: Values of aortic vascular stiffness (ASI) in TAK patients compared with controls (hypertensive and atherosclerotic patients) (A). ASI values are directly related to the degree of LV diastolic dysfunction (B) and uric acid (UA) levels (C) in TAK patients. Common carotid intimamedia thickness (IMT) shows an inverse correlation with aortic diameter indexed by body surface area (BSA) (Aoi) (D) and aortic wall thickness (E), and a direct correlation with ASCVD 10-year risk rate (F) in TAK patients. Evaluation was performed excluding already known cardiovascular disease (B-C) and those who underwent to surgical treatment (D-F).

A statistically significant increase in aortic wall thickness was measured in TAK patients compared with hypertensive and atherosclerotic patients (1.93 $\pm 0.79 / 1.66 \pm 1.32$ ) (Table 3). Standard carotid intima-media thickness (IMT) showed no difference between patients in both 
groups. However, in the TAK patients who did not undergo to surgical treatment, the thickness of the common carotid wall was inversely related to the aortic diameter when indexed with the BSA (Aoi), as well as to the aortic wall thickness (Figures 2D-E). Interestingly, IMT of the common carotid artery was significantly correlated with atherosclerotic cardiovascular disease (ASCVD)-10$\mathrm{yr}$ (Figure 2F). These data suggest that cardiovascular risk in TAK is increased by enhanced vascular remodeling rather than by classic risk factors.

Immune cells and vascular involvement

A significant decrease in peripheral blood lymphocyte count was observed in TAK patients compared to hypertensive and atherosclerotic patients (1584.4 $\pm 554.6 / 2178.6 \pm 626.5$, Table 4). No other significant differences were observed between the two groups. As expected, erythrocyte sedimentation rate (ESR) $(41.48 \pm 31.49 / 10.15 \pm 6.79)$ and C-reactive protein (CRP) values (46.30 \pm $57.44 / 3.01 \pm 0.45)$ were significantly higher in TAK patients than in hypertensive and atherosclerotic patients (Table 4).

Table 4: Peripheral blood immunological parameters of enrolled patients.

\begin{tabular}{|c|c|c|c|}
\hline Characteristic & TAK & Arterial Hypertension & p Value \\
\hline Total WBC count & $7226.3 \pm 1823.4$ & $8337.8 \pm 3274.6$ & Ns \\
\hline Lymphocytes & $1584.4 \pm 554.6$ & $2178.6 \pm 626.5$ & 0.01 \\
\hline $\mathrm{CD}^{+}($cell $/ \mathrm{ml})$ & $1331.1 \pm 504.0$ & $1864.2 \pm 784.6$ & Ns \\
\hline $\mathrm{CD}^{+}{ }^{+} \mathrm{HA}^{-\mathrm{DR}^{+}}(\%)$ & $3.75 \pm 3.59$ & $3.50 \pm 2.08$ & Ns \\
\hline $\mathrm{CD}^{+} \mathrm{CD}^{+}($cell $/ \mathrm{ml})$ & $738.8 \pm 301.8$ & $1064.3 \pm 544.5$ & Ns \\
\hline $\mathrm{CD}^{+} \mathrm{CD}^{+}($cell $/ \mathrm{ml})$ & $560.3 \pm 250$ & $719.0 \pm 325.5$ & Ns \\
\hline $\mathrm{CD}^{+} \mathrm{CD} 16 / 56^{+}$(cell/ml) & $135.7 \pm 98.86$ & $226.9 \pm 167.0$ & Ns \\
\hline $\mathrm{CD} 19^{+}($cell $/ \mathrm{ml})$ & $123.0 \pm 159.7$ & $156.7 \pm 104.9$ & Ns \\
\hline Neutrophils (cell/ml) & $4902.2 \pm 2193.4$ & $5536.2 \pm 2702.2$ & Ns \\
\hline NLR & $4.43 \pm 4.17$ & $2.94 \pm 2.07$ & Ns \\
\hline $\mathrm{ESR}(\mathrm{mm} / \mathrm{h})$ & $41.48 \pm 31.49$ & $10.15 \pm 6.79$ & 0.0001 \\
\hline CRP (mg/dl) & $46.30 \pm 57.44$ & $3.01 \pm 0.45$ & 0.0001 \\
\hline C3 (g/L) & $1.19 \pm 0.26$ & $1.24 \pm 0.28$ & Ns \\
\hline
\end{tabular}

$\mathrm{WBC}=$ white blood cells; $\mathrm{NLR}=$ neutrophil to lymphocyte ratio; $\mathrm{ESR}=$ erythrocyte sedimentation rate; $\mathrm{CRP}=\mathrm{C}$-reactive protein; $\mathrm{C} 3=$ Complement component 3 .

Based on the immunological analysis, we found that ASI values were negatively correlated with peripheral total white blood cell counts (WBCs), neutrophils and $\mathrm{CD} 3^{+} \mathrm{CD} 8^{+}, \mathrm{CD} 3^{+} \mathrm{HLA}-\mathrm{DR}{ }^{+}$ counts, and neutrophil-to-lymphocyte ratio (NLR). Conversely, ASI values showed a significant positive correlation with total lymphocyte count and total $\mathrm{CD}^{+}$and $\mathrm{CD}^{+} \mathrm{CD}^{+}$cell count (Table 5). 
A positive significant correlation was found for aortic wall thickness with $\mathrm{CD}^{+} \mathrm{HLA}-\mathrm{DR}{ }^{+}$and $\mathrm{CD}^{+}{ }^{+} \mathrm{CD} 4^{+}$peripheral cells, while this vessel parameter had a significant negative correlation with the total number of $\mathrm{CD}^{+}, \mathrm{CD}^{+} \mathrm{CD}^{+}$and NLR (Table 6). Finally, SBP levels were significantly correlated with ASI (Table 5) but negatively correlated with aortic wall thickness (Table 6).

The final results may suggest that increased vascular inflammation in TAK patients leads to a loss of vascular compliance.

Table 5: Pearson correlation analysis between Aortic Stiffness Index and peripheral blood immunological parameters and blood pressure of Takayasu patients.

\begin{tabular}{|c|c|c|}
\hline Characteristic & $\mathbf{R}$ & p Value \\
\hline Total WBC count & -0.85 & 0.007 \\
\hline Lymphocytes & 0.91 & 0.002 \\
\hline $\mathrm{CD}^{+}$ & 0.97 & 0.001 \\
\hline $\mathrm{CD}^{+} \mathrm{HLA}^{-} \mathrm{DR}^{+}$ & -0.98 & 0.0005 \\
\hline $\mathrm{CD}^{+} \mathrm{CD}^{+}$ & 0.75 & 0.03 \\
\hline $\mathrm{CD}^{+} \mathrm{CD}^{+}$ & -0.84 & 0.008 \\
\hline $\mathrm{CD}^{+} \mathrm{CD} 16 / 56^{+}$ & 0.16 & Ns \\
\hline $\mathrm{CD}_{19}{ }^{+}$ & 0.32 & Ns \\
\hline Neutrophils & -0.93 & 0.001 \\
\hline NLR & -0.97 & 0.001 \\
\hline ESR & 0.21 & Ns \\
\hline CRP & 0.02 & Ns \\
\hline Uric Acid & 0.57 & 0.04 \\
\hline SBP & 0.68 & 0.03 \\
\hline
\end{tabular}

$\mathrm{WBC}=$ white blood cells; NLR= Neutrophil-Lymphocyte Ratio; $\mathrm{ESR}=$ Erythrocyte sedimentation rate; $\mathrm{CRP}=\mathrm{C}-$ reactive protein; $\mathrm{SBP}=$ Systolic Blood Pressure.

Table 6: Pearson correlation analysis between Aortic wall thickness and peripheral blood immunological parameters and blood pressure of Takayasu patients.

\begin{tabular}{ccc}
\hline Parameter & $\mathbf{R}$ & p Value \\
\hline Total WBC count & 0.009 & Ns \\
Lymphocytes & -0.91 & 0.0007 \\
CD3 $^{+}$ & -0.79 & 0.005 \\
\hline
\end{tabular}




\begin{tabular}{ccc}
\hline $\mathrm{CD}^{+} \mathrm{HLA}^{-} \mathrm{RR}^{+}$ & 0.86 & 0.003 \\
$\mathrm{CD}^{+} \mathrm{CD}^{+}$ & 0.62 & 0.03 \\
$\mathrm{CD}^{+} \mathrm{CD}^{+}$ & -0.87 & 0.003 \\
$\mathrm{CD}^{+} \mathrm{CD} 16 / 56^{+}$ & -0.09 & $\mathrm{Ns}$ \\
$\mathrm{CD} 19^{+}$ & -0.09 & $\mathrm{Ns}$ \\
$\mathrm{Neutrophils}$ & 0.27 & $\mathrm{Ns}$ \\
$\mathrm{NLR}$ & -0.97 & 0.001 \\
$\mathrm{ESR}$ & -0.44 & $\mathrm{Ns}$ \\
$\mathrm{CRP}$ & -0.31 & $\mathrm{Ns}$ \\
Uric Acid & -0.44 & $\mathrm{Ns}$ \\
SBP & -0.55 & 0.049 \\
\hline
\end{tabular}

$\mathrm{WBC}=$ white blood cells; NLR= Neutrophil-Lymphocyte Ratio; $\mathrm{ESR}=$ Erythrocyte sedimentation rate; $\mathrm{CRP}=\mathrm{C}-$ reactive protein; $\mathrm{SBP}=$ Systolic Blood Pressure.

\section{Immune cell infiltration in TAK and hypertensive and atherosclerotic patients}

To confirm the possible relationship between infiltration by immune cells and the extent of vascular lesions in TAK patients, ex vivo experiments were performed on blood vessel sections from both groups of patients.

A significant increase in $\mathrm{CD}^{+}, \mathrm{CD}^{+}$, and $\mathrm{CD}^{+}$cell infiltration was observed in samples from TAK patients compared with controls (Figure 3). High-mobility group box 1 (HMGB1) staining, which labels immunological inflammatory cells, was also significantly higher in the TAK group (Figure 3).

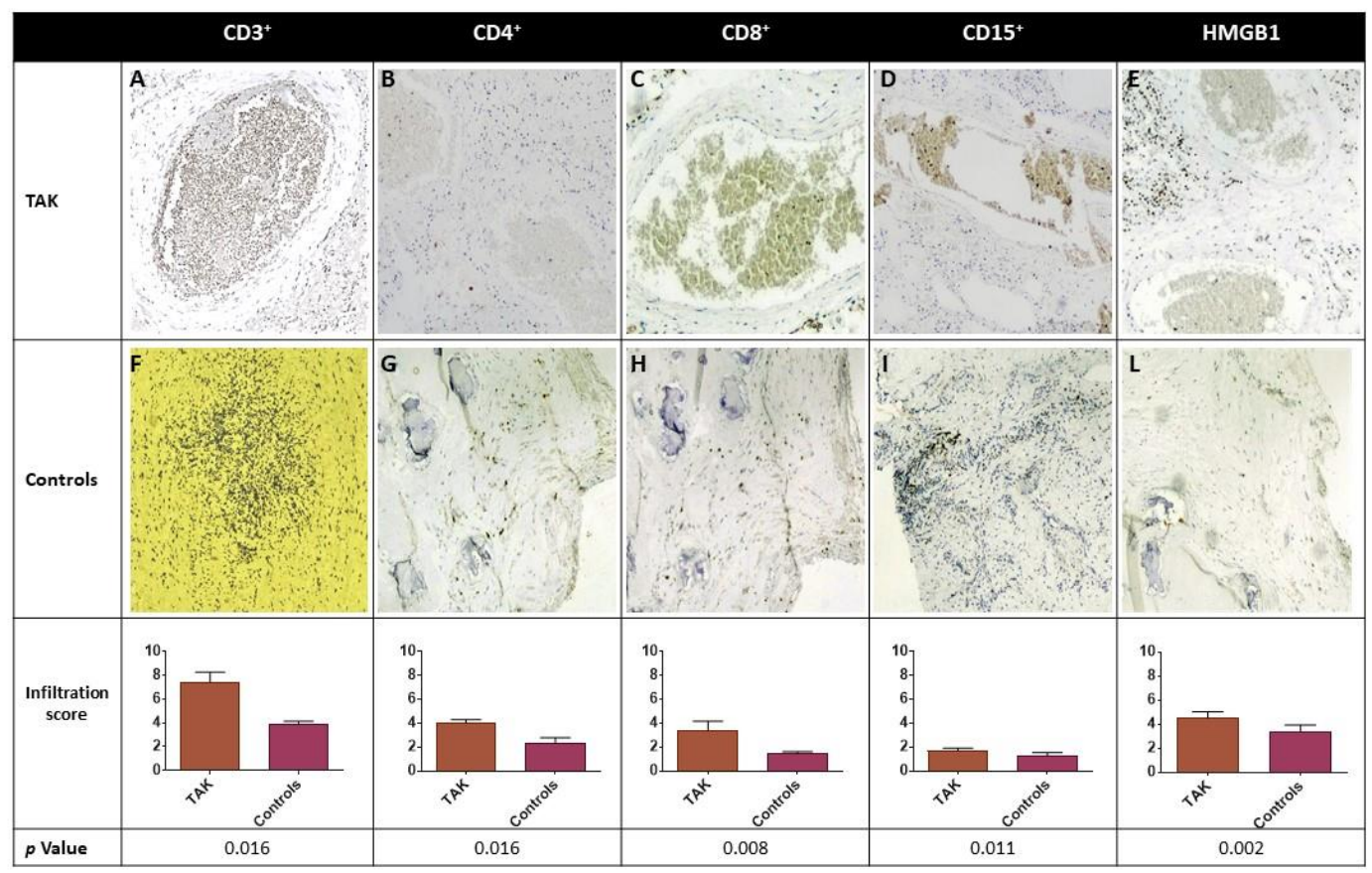


Figure 3: Immune cell infiltration $\left(\mathrm{CD}^{+}, \mathrm{CD}^{+}, \mathrm{CD}^{+}\right.$and $\left.\mathrm{CD} 15^{+}\right)$and expression level of inflammation-associated cytokines of vascular injury HMGB1 in biopsy samples from blood vessels of TAK patients $(A, B, C, D, E)$ and controls $(F, G, H, I, L)$. Representative immunohistochemistry (original magnification: $10 \mathrm{X}$ ) is shown in the top and middle panels. The lower panel shows the results as mean \pm S.D. of three independent experiments for each field.

To evaluate neutrophilic vessel wall infiltration, $\mathrm{CD}_{1} 5^{+}$immune cells were stained and found significantly higher in TAK-derived vessels than in samples from hypertensive and atherosclerotic patients (Figure 3). Moreover, in TAK vessels, there was a significant direct correlation between $\mathrm{CD}^{+}$( $T$ helper or Th) cell infiltration and $\mathrm{CD} 15^{+}$cells $(r=0.800, p=0.038)$, but not with the total number of $\mathrm{CD}^{+}$or $\mathrm{CD} 8^{+}$cells. Both $\mathrm{CD}_{1} 5^{+}$and $\mathrm{CD}^{+}$cells were directly correlated with HMGB1 ( $r=0.894, p=0.029$ ) (Figure 3$)$, suggesting an association with inflammation-related vascular damage. No significant histological correlation was observed in hypertensive and atherosclerotic patients.

Similar to previous observations, histology confirms that infiltration by immune cells is more related to vascular damage and release of chemotactic cytokines.

\section{Frequency of Treg and Th17 cells}

In a subpopulation of sixteen TAK patients treated with infliximab, the frequency of CD4 ${ }^{+}$FoxP3 ${ }^{+}$Tregs and $\mathrm{CD}^{+}{ }^{+} \mathrm{CD} 4^{+}$interleukin (IL)- $17^{+}$cells was assessed before (time $0, \mathrm{TO}$ ) and after 18 months of treatment (time 18, T18) (Figure 4A). A subset of 15 hypertensive and atherosclerotic patients served as controls. Flow cytometry was performed on freshly isolated peripheral blood mononuclear cells (PBMCs) stimulated with phorbol 12-myristate 13-acetate (PMA) and ionomycin. At TO, the mean percentage of Tregs was significantly reduced in TAK patients $(0.22 / 0.67, \mathrm{p}<0.0001)$ compared to hypertensive and atherosclerotic patients and significantly increased at T18 $(0.22 / 0.86, p<0.001)$ (Figure $4 B$ ). At the same time, the frequency of $\mathrm{CD}^{+} \mathrm{CD} 4^{+} \mathrm{IL}-17^{+}$cells indicating IL-17 expression behaved in the opposite way. The higher number of Th17 cells observed in TAK patients at T0 $(3.2 / 1.4, p<0.0001)$ significantly decreased at T18 $(3.2 / 2.2, p<0.001)$ (Figure $4 \mathrm{C}$ ), probably due to infliximab treatment.
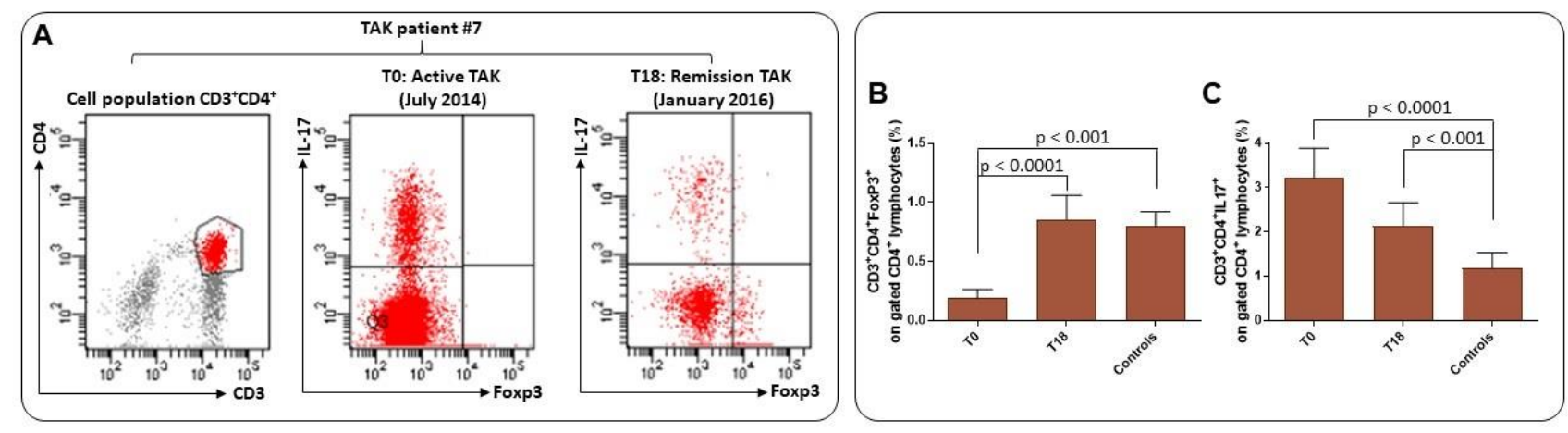

Figure 4: Frequency of Treg and Th17 cells in TAK patients and hypertensive and atherosclerotic controls. (A) Flow cytometry analysis: gating was performed on live $\mathrm{CD} 3^{+} \mathrm{CD} 4^{+}$cells to identify Foxp3+Treg and IL-17+ cells. Representative plots from one patient for each group. (B) Results are presented as mean \pm S.D. of $\mathrm{CD}^{+}{ }^{+} \mathrm{CD}_{4}{ }^{+} \mathrm{Foxp}^{+}$percentages and $\mathrm{CD}^{+}{ }^{+} \mathrm{CD} 4^{+} \mathrm{IL}-17 \mathrm{~A}^{+} \mathrm{T}$ cells $(\mathrm{C})$ in TAK patients before (TO) and after 18 months (T18) of infliximab treatment and in matched hypertensive and atherosclerotic patients as controls (Wilcoxon signed-rank test and unpaired $t$ test, Mann-Whitney test). 
Taken together, these results may support the idea that biologic therapy may be useful to achieve better control of TAK and achieve a Treg/Th17 score similar to that of hypertensive patients. Further prospective and larger studies should be useful to understand whether these results may allow a possible reduction in steroid and immunosuppressant dose and lead to a reduction in cardiovascular risk.

\section{Discussion}

This cross-sectional, single-center study aimed to investigate the potential association between parameters of vascular and cardiac impairment, infiltration of immune cells into vessel tissue, and overall risk of cardiovascular events in TAK patients. Patients with essential (idiopathic) hypertension and atherosclerosis, whose cardiovascular risk factors are well known, were selected as a control group.

The development of atherosclerosis is a recognized cardiovascular risk factor, and steroid therapies can have significant side effects on the lipid spectrum, with a notable impact on total and LDL cholesterol levels [27]. Although steroid treatment is expected to prolong the life expectancy of TAK patients, it may contribute to an increased risk of cardiovascular events through dysregulation of plasma lipid levels. In our study, TAK patients had lower levels of total and LDL cholesterol compared with hypertensive and atherosclerotic patients, with no significant difference in HDL cholesterol or triglyceride levels between the two groups.

Due to the disease-related pathophysiological changes in vascular compliance, blood pressure levels are often elevated in TAK patients [28]. However, while systolic blood pressure (SBP) values in TAK patients were similar to those in hypertensive and atherosclerotic patients, diastolic blood pressure (DBP) values in both left and right arms were significantly lower in TAK patients. As in hypertensive and atherosclerotic patients $[28,29]$, these results demonstrate that accelerated arterial stiffness and concomitant higher pulse wave velocity progression in our TAK patients may contribute to a significant increase in SBP and concomitant decrease in DBP values.

On echocardiographic ultrasound, the parameters of cardiovascular dysfunction in the TAK patients were comparable to those in the hypertensive and atherosclerotic patients: Both groups showed similar increases in LVM, IVS, and LAV. Similar to hypertensive patients [31,32], concentric left ventricular hypertrophy is also frequently observed in TAK patients [33].

Mild-to-moderate and moderate-to-severe aortic regurgitation were observed in our TAK patients, with the most severe conditions correlating with the highest serum uric acid levels. Aortic regurgitation may be the result of aortic root dilatation [34], the risk of which increases in parallel with the rise in serum uric acid levels [35]. According to recent epidemiological studies, elevated uric acid levels have been associated with the development of hypertension [35] and dyslipidemia [36], leading to a predictive marker for cardiovascular events [37]. Uric acid enhances the transcription of nuclear factor-KB [38], which has pro-inflammatory and pro-atherogenic effects in the vascular wall [39], as it stimulates the production of inflammatory cytokines, including TNF- $\alpha$ [40], and the release of C-reactive protein [41]. This protein in turn enhances the expression of cellular adhesion molecules, promotes cellular apoptosis, and leads to endothelial dysfunction and arterial stiffness [42]. In addition, high uric acid levels have a pro-oxidant effect, triggering the oxidation of lipoproteins [43] while limiting the bioavailability of nitric oxide in the arterial wall [44-47]. The decreased bioavailability of nitric oxide promotes endothelial dysfunction, increases vascular tone and consequently arterial stiffness $[47,48]$. Interestingly, in our TAK patients, diastolic dysfunction worsened with the increase in uric acid levels. The positive correlation found between increased ASI, uric acid levels and the degree of diastolic dysfunction in TAK patients explains the LV remodeling process in these patients. 
LAVi was higher in TAK patients than in hypertensive and atherosclerotic patients. In addition to pressure and volume overload [49], LAV increases in conditions with systemic inflammation such as autoimmune diseases [14] or pneumonia [50]. The potential prognostic value of LAV dimensions for cardiovascular risk in TAK patients is interesting but deserves further investigation.

Carotid intima/media thickness (IMT), a surrogate marker of cardiovascular risk factors and ASCVD, was equally increased in both groups; in TAK patients, IMT was inversely correlated with aortic wall thickness. This suggests that inflammatory burden in TAK patients may represent an independent risk factor for cardiovascular or atherosclerosis-related disease, similar to canonical risk factors in hypertensive and atherosclerotic patients.

According to other reports [51-54], a significant decrease in total lymphocytes in peripheral blood and considerable infiltration of $\mathrm{CD}^{+}, \mathrm{CD}^{+}$, and $\mathrm{CD} 8^{+} \mathrm{T}$ cells in the arterial wall was observed in TAK patients during the active phase. The vessel wall also exhibited granulomatous infiltrates of $\mathrm{CD}^{+} \mathrm{T}$ cells and macrophages, neovascularization, loss of smooth muscle cells in the tunica media with damage to elastic membrane lamellae and elastin fibers, and growth of a lumen-constricting neointima, which may explain the increased ASI in these patients. Further evidence for these data is that ASI was positively correlated with total peripheral lymphocyte count and total $\mathrm{CD}^{+}$and $\mathrm{CD}^{+} \mathrm{CD}^{+}$T-cell counts. While hypertension is associated with increased aortic stiffness independent of aortic wall thickness [22], we can therefore speculate that $\mathrm{CD} 3^{+}, \mathrm{CD}_{4}^{+}$, and $\mathrm{CD} 8^{+} \mathrm{T}$ cell infiltrates and the resulting fibrotic outcomes are behind the increased ASI and aortic wall thickness in our TAK patients.

Inflammation of vessel walls, mechanical or immune-mediated injury, and ischemia/reperfusion of tissues lead to the release of HMGB1 (High Mobility Group Box 1), a small nuclear protein that promotes DNA bending and preferential assembly of transcription factors at specific DNA domains [54,55]. When HMGB1 is secreted by activated immune cells into the extracellular environment, it acts on all cell populations involved in vascular inflammation and functions as a candidate signaling protein for the transition from acute inflammation to selfsustaining chronic inflammation in large vessel vasculitis [54,55]. Injured endothelial cells release HMGB1 [56] and attract endothelial cell progenitors that promote neovascularization [57]. In addition, HMGB1 activates dendritic cells and promotes their functional maturation and responsiveness to chemokines and regulates cell migration [54]. HMGB1 also attracts myocyte precursors and vessel-associated stem cells [58], which are required for intimal hyperplasia/angiogenesis typical of vessel remodeling in large vessel vasculitides [59]. The significant increase in HMGB1 immunostaining in the arterial wall of our TAK patients and the direct correlation between HMGB1 and infiltration of $\mathrm{CD} 15^{+}$and $\mathrm{CD} 4^{+}$cells support the existence of a vicious circle that enhances autocrine/paracrine release of HMGB1 [55,56,61,62] and alters vascular morphology and hemodynamic balance in TAK patients.

Compared with hypertensive and atherosclerotic patients, TAK patients had a high frequency of $\mathrm{CD}^{+} \mathrm{CD} 4^{+} \mathrm{IL}-17^{+}$cells, indicating increased IL-17 expression, and lower levels of CD4 ${ }^{+}$FoxP3 ${ }^{+}$Treg cells in peripheral blood. Compared to TAK patients receiving standard steroid therapy alone, infliximab co-treated patients showed significant improvement in clinical symptoms, allowing steroids to be discontinued more quickly. When these patients were assessed at $\mathrm{T} 18$ of combined therapy with infliximab, $\mathrm{CD} 3^{+} \mathrm{CD} 4^{+} \mathrm{IL}-17^{+}, \mathrm{CD} 4^{+}$, and FoxP3 ${ }^{+} \mathrm{Treg}$ cells substantially overlapped levels of hypertensive and atherosclerotic patients. These results suggest that biologic therapy is highly effective compared with standard treatment in both improving clinical symptoms and controlling disease pathophysiology, as demonstrated by the more rapid de-escalation of daily prednisone dose and normalization of Tregs and Th17 cell frequency, and that infliximab facilitates immunologic balance in TAK patients as in hypertensive and 
atherosclerotic patients. Although these results are still preliminary and limited, they may serve as first evidence for future, statistically powered studies to examine the impact of biologic treatments on clinical outcomes in larger groups of TAK patients. In particular, it will be important to determine whether infliximab treatment can slow down, or even prevent the cardiovascular impairments associated with worsening of inflammatory status in TAK patients.

\section{Materials and Methods}

\section{Patients and study design}

This cross-sectional single-centre study was conducted in conformity to the Good Clinical Practice Guidelines of the Italian Ministry of Health and the ethical guidelines of the Declaration of Helsinki (as revised and amended in 2004) and with the approval of the Ethics Committee of the University of Bari Medical School (Code number 06R76Y9-1). Informed consent was obtained from all patients. To avoid any influence in method evaluation of left ventricle function, exclusion criteria were secondary causes of hypertension, atrial fibrillation, heart failure with reduced or mid-range Ejection Fraction, lung disease and pulmonary arterial hypertension.

Thirty TAK patients ( $22 \mathrm{~F}, 8 \mathrm{M}$, aged $49 \pm 14$ years) were consecutively enrolled and followed-up from January 2014 to December 2018 among patients with large vessel vasculitis admitted to our Centre. Patients met the European League against Rheumatism criteria for large vessel vasculitides [62]. Patients were in the active phase of the disease (ITAS-A $>6$ ) and were clinically assessed before (time point T0) and 18 months after (T18) treatment with standard therapy and infliximab. The control group consisted of 30 age- and sex-matched patients ( $22 \mathrm{~F}, 8 \mathrm{M}, 51 \pm 12$ years old) who were diagnosed with idiopathic hypertension and had no history of chronic viral infection, autoimmune disease, immune-mediated disease, hematologic malignancies, or cancer. All patients underwent a comprehensive medical examination, including medical history (age, sex, smoking habits, drug treatment, concomitant diseases) and physical examination.

In both groups, correlations were done excluding patients affected by history of ischemic heart disease and heart failure.

\section{Clinical and laboratory evaluation}

Blood pressure values were measured with an electronic sphygmomanometer and were reported as the mean of three consecutive in-office measurements in the supine position after 15 minutes of rest. The 10-year estimation of the risk of cardiovascular events was performed for all patients using the ACC/AHA validated ASCVD score [63].

Complete routine laboratory tests included ESR, creatinine, blood glucose, total cholesterol, HDL, LDL, triglycerides, uric acid, CRP, and C3 complement fraction. A standard lymphocytogram was performed in 10 TAK and control patients.

\section{Ultrasound evaluation}

A standardized method included a transthoracic echocardiogram with Doppler evaluation (ETG) and ultrasonography Doppler evaluation (SAD) of the supra-aortic vessels [64]. All ultrasound measurements were performed with a $2.5-\mathrm{MHz}$ probe (MyLabSeven Doppler echocardiography device, Esaote, Italy) in the left lateral decubitus position; SAD was performed with a $12-\mathrm{MHz}$ linear probe (MyLabSeven Doppler device, Esaote, Italy) on the relaxed neck in the supine position.

1. Echocardiogram and cardiac Doppler - Using a previously standardized flow-chart [65], twodimensional echocardiography was performed to measure aortic root diameter (Ao) in parasternal long-axis view during both systolic (AoS) and diastolic phases (AoD) by an ECG- 
guided point measurement. In the same position, one-dimensional echocardiography (Mmode) was used to obtain end-diastolic measurements of interventricular septum thickness (IVS), posterior wall thickness (PWD), and left ventricular internal diameter (LVD). According to the international guidelines, the left ventricular mass (LVM) was calculated using the Devereux formula for M-mode diameters. Relative wall thickness (RWT) was calculated using the international validated formula [66]. An apical four-chamber view (A4C) was used to measure tricuspid annular plane systolic excursion (TAPSE) and right atrial area (RA). The A4C view was used to measure left ventricular end-diastolic volume (LVEDV), ejection fraction (EF), and left atrial volume (LAV). Sub-costal view (SC) was used to measure inferior vena cava diameter (CVD). Ao, LAV and LVM were indexed to body surface area (BSA) and height 2.7 (LVMi2.7) [63]. Aortic root stiffness was assessed using the Aortic Stiffness Index (ASI = In (SBP /DBP)/[(AoS - AoD) /AoD] [67].

Doppler measurements were performed in the A4C B-mode view. The velocity of tricuspid regurgitation (TRV) was determined using a continuous wave Doppler curve of tricuspid regurgitation (TR) trace. The peak value of TRV was used to measure the pressure difference between the right ventricle and right atrium (RA) according to the simplified Bernoulli equation $\left(P=4[T R m a x]^{2}\right)$. RA filling pressure was estimated from the diameter and respirophasic variability of the inferior vena cava during normal breathing. The pulmonary arterial pressure (PAP) estimate was a derived sum of RA filling pressure and TR pressure. In the same view, pulsed-wave Doppler was used to measure transmitral velocity $E$ and $A$ and septal velocity $\mathrm{e}^{\prime}$ in tissue Doppler imaging (TDI) mode. Diastolic dysfunction was assessed as the combination of mitral ratio $\mathrm{E} / \mathrm{A}$ and $\mathrm{E} / \mathrm{e}^{\prime}$ and were stratified as indicated in guidelines [66].

2. Carotid ultrasound Doppler - This was performed to assess vascular damage. Intima-media thickness (IMT) was measured using basal B-mode imaging. Selecting the best view of the common carotid artery, radiofrequency analysis yields the mean IMT based on ten automated measurements taken on the posterior wall of the common carotid artery at a length of $1 \mathrm{~cm}$ and $1 \mathrm{~cm}$ distal to the vessel bifurcation. Blood flow was analyzed with PW Doppler at a standard angle of $60^{\circ}$, measuring the flow of the common and internal carotid arteries. The North American Symptomatic Carotid Endarterectomy Trial (NASCET) method was used to quantify arterial stenosis and atherosclerosis [68].

\section{Histological analysis}

Ten TAK patients and eight hypertensive patients with atherosclerotic lesions underwent to surgery to open critical supraaortic vessel stenosis. Therefore, we analyze surgical samples to understand immune cell infiltration. Samples were fixed in neutral $10 \%$ buffered formalin, dehydrated and enclosed in paraffin. $5 \mu \mathrm{m}$ thick slices were taken from the paraffin-embedded blocks, deparaffinized, rehydrated and routinely stained with hematoxylin-eosin. Immunohistochemistry was then performed using antibodies for the following markers: mouse monoclonal Ab (mAb) anti-CD4 (DAKO, Carpinteria, CA, USA), anti-CD8 (Novacastra Laboratories Ltd.), anti-CD3 (DAKO) and anti-CD15 (DAKO).

To study the infiltration of immune cells, the expression of HMGB1 [55] was assessed using polyclonal rabbit anti-HMGB1 serum (Ab18256, Abcam, Cambridge, USA). Blocks were pretreated on PT-LINK (DAKO) instrument with EDTA [EnVision Flex, Target Retrieval Solution, High Ph (50x), DAKO] for CD3, CD4, CD8 antibodies and Citrate [EnVision Flex, Target Retrieval Solution, Low Ph (50x), DAKO] for HMGB1 antibodies. Immunohistochemistry was performed to measure the density of $\mathrm{CD}^{+}$and $\mathrm{CD}^{+}$cells in 10 fields at $400 \mathrm{x}$ magnification of each sample. One field measured 140 micrometers in length and 110 micrometers in width, and the total amplitude was 15,400 micrometers squared. A Reichert Polyvar 2 microscope with a JTV digital telecamera and a 
Trinitron monitor (Sony) was used. HMGB1 expression was assessed by highlighting the chromogen signal on the plasma membrane, nucleus, cytoplasm or extracellular medium of the samples examined. The expression level was calculated by adding the degree of staining intensity (grade $0=$ no staining; grade $1=$ weak staining; grade $2=$ moderate staining; grade $3=$ intense staining) with the percentage of mass extension (score 0: $<1 \%$; score 1: $1-25 \%$; score 2: $26-50 \%$; value 3: $51-74 \%$; score $4: \geq 75 \%$ ). The resulting final scores were rated as high (if $>3$ ) or low (if $\leq 3$ ). After processing, two different expert pathologists scored the samples. The final value was described as the mean of the two values.

\section{Biological samples and cell preparations}

Sera were obtained after centrifugation of clotted blood samples and stored at $-20^{\circ} \mathrm{C}$ until further analysis. PBMCs were isolated from heparinized samples using Ficoll-Hypaque (GE Healthcare Life Sciences) gradient separation. $\mathrm{CD} 4{ }^{+} \mathrm{CD} 25^{+} \mathrm{CD} 127 \%$ dim $\mathrm{T}$ cells were purified using the $\mathrm{CD} 4{ }^{+} \mathrm{CD} 25^{+} \mathrm{CD} 127 \%$ dim regulatory $\mathrm{T}$ Cell Isolation Kit II (Miltenyi Biotec, Auburn, CA, USA). The obtained cell populations had a purity of $95 \%$ as shown by flow cytometry on immunostained cells.

\section{Cell cultures and stimulation}

PBMCs $\left(6 \times 10^{5} /\right.$ well) were cultured in triplicate in 96-well round-bottom plates in $200 \mathrm{ml}$ of Roswell Park Memorial Institute (RPMI) 1640 medium supplemented with 10\% of heat-inactivated FBS, $2 \mathrm{mM}$ of L-glutamine, $100 \mathrm{U} / \mathrm{ml}$ of penicillin, and $100 \mathrm{mg} / \mathrm{ml}$ of streptomycin (all from SigmaAldrich, St Louis, MN, USA). Cells were untreated and/or treated with $10 \mathrm{ng} / \mathrm{ml}$ of PMA and 1 $\mathrm{mg} / \mathrm{ml}$ of ionomycin (all from Sigma-Aldrich) for 18 hours in a humidified atmosphere containing $5 \% \mathrm{CO} 2$. After five hours, $3 \mu \mathrm{M}$ of monensin was added to block Golgi transport (Sigma-Aldrich). Cells were then harvested and immunostained.

\section{Cytofluorimetric staining}

A set of commercial monoclonal antibodies (mAbs) have been used in flow cytometry to analyze the expression of Tregs. Peridinin-chlorophyll proteins cyanine 5.5 conjugated (Perce) anti-CD4 mAb, phycoerythrinCyanine7 conjugated (PECy7) anti-IL-17 mAb, and the alloficocianinconjugated (APC) anti-Foxp3 mAb were all part of the Human Th17/Treg phenotyping kit (Becton Dickinson-BD Biosciences, San Jose, CA, USA). Fluorescein isothiocyanate (FITC) conjugated antiCD4 mAb and FITC conjugated anti-CD3 mAb were purchased from Beckman Coulter (Brea, California, USA). Cells were incubated with mAbs to surface antigens for 30 minutes at $4^{\circ} \mathrm{C}$ and then washed twice in cold phosphate-buffered saline (PBS) (Sigma-Aldrich) containing $0.1 \%$ fetal bovine serum (FBS) (Sigma-Aldrich) before flow cytometry was performed. To determine Th17/Treg phenotype, cells were fixed, permeabilized, and stained according to the manufacturer's instructions for the Human Th17/Treg Phenotyping Kit (BD Biosciences). Stained cells were acquired using FACSCanto II cytofluorimetry (BD Biosciences) and analyzed using FACSDiva software (BD Biosciences).

\section{Statistics}

Data were analyzed using GraphPad Prism software (La Jolla, CA, USA) and expressed as means \pm S.D. Chi-square test was performed to analyze the distribution of dichotomous values. The nonparametric Mann-Whitney test for comparisons and Spearman distribution for correlations were performed for non-normally distributed data. The parametric unpaired t-test for comparisons and Pearson distribution for correlations were performed for normally distributed data. A value of $p<$ 0.05 was taken as an indication of statistical significance. 


\section{Limits of the study and Conclusions}

This study has clear limitations. Firstly, it was a single centre study with small sample size, warranting future statistically powered studies in order to evaluate, in a proper prospective analysis, the impact on clinical outcome in terms of survival. All echocardiographic analyses could be significantly influenced by the quality of ultrasound images. Due to the disease studied, the hemodynamic state of right heart was evaluated only with ultrasound and no data on right heart catheterization were available. Additionally, all patients with comorbidities such as atrial fibrillation or lung disease were excluded, reducing the potential generalization of our results. Finally, TAK patients were most under steroid treatment while controls were under antihypertensive treatment, thus inducing the vascular compliance. However, to our knowledge, there are no previous data analysing cardiovascular risk in patients affected by TAK or the role of immune cells in cardiovascular risk in these patients.

Overall, the results of our study suggest that the severity of large vessel damage is higher in TAK patients than in hypertensive patients. The histological data suggest different pathogenic mechanisms underlying TAK or atherosclerosis. Interestingly, the increased ASCVD risk in TAK patients seems to be directly related to infiltration of the vessel wall by inflammatory cells, and damage-associated molecular patterns may play a key role in this mechanism. This may suggest that in systemic inflammation and vasculitis, optimal disease control may also reduce the residual risk of cardiovascular disease. As shown by our preliminary results on infliximab treatment, this drug seems to be particularly effective in restoring the normal frequency of Tregs and Th17 cells in TAK patients. On this basis, assessment of Tregs and Th17 populations could serve as a potential biomarker to monitor treatment efficacy and as a novel therapeutic target to reduce cardiovascular risk in TAK patients.

\section{Funding}

This work was supported: by "Programma Regionale" - Research for Innovation REFIN - POR Puglia FESR-FSE 2014/2020; INNOLABS-POR Puglia FESR-FSE 2014-2020 (CITEL-Telemedicine Reasearch Center) and "Progetto Regione Puglia - Fondo europeo di sviluppo regionale e Fondo sociale europeo (FESR e FSE)"

The sponsors of this study are public or non-profit organizations that support science in general.

Author Contributions: Conceptualization, S.C., V.D.; methodology, S.C., V.D., C.S., G.C.; validation, S.C., V.D., C.S., A.V., M.A.F. and G.I.; formal analysis, S.C., V.D.; investigation, S.C., V.D., A.Cir., G.C., S.N., C.S. and M.P.; data curation, S.C., V.D., A.V.; writing-original draft preparation, S.C., V.D., A.V.; writing-review and editing, A.G.S., G.B., C.C., A.Cim., L.R., R.R., M.M.; visualization, A.L., I.S.; supervision, R.R., M.M.

All authors have read and agreed to the published version of the manuscript.

\section{Conflict of interest:}

The authors declared no potential conflicts of interest with respect to the research, authorship, and/or publication of this article. 


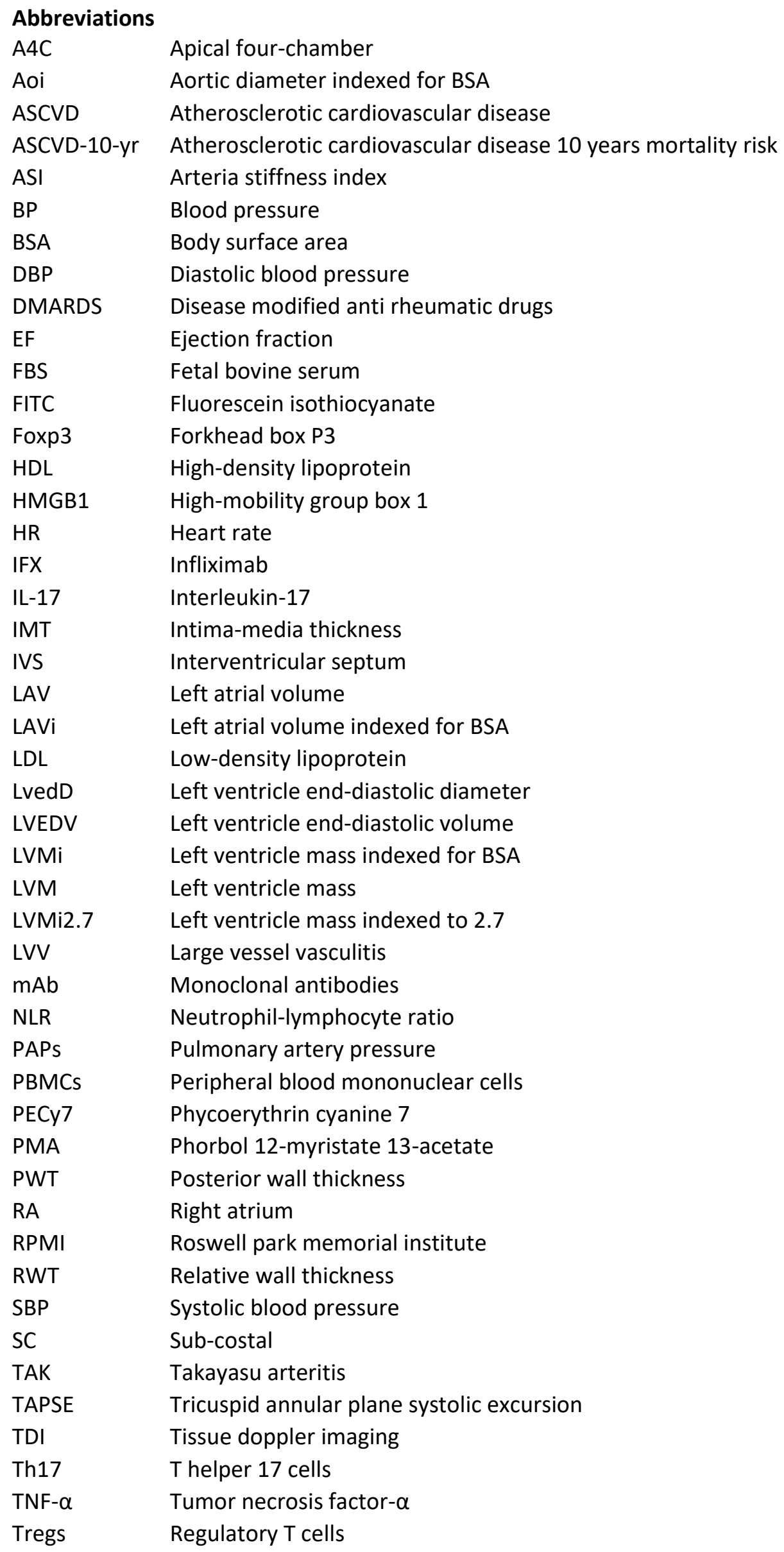




\section{References}

1. Berti, A.; Moura, M.C.; Sechi, E.; Squizzato, F.; Costanzo, G.; Chen, J.J.; Warrington, K.J. Beyond Giant Cell Arteritis and Takayasu's Arteritis: Secondary Large Vessel Vasculitis and Vasculitis Mimickers. Curr. Rheumatol. Rep. 2020, 22, doi:10.1007/s11926-020-00965-w.

2. Vanoli, M.; Daina, E.; Salvarani, C.; Sabbadini, M.G.; Rossi, C.; Bacchiani, G.; Schieppati, A.; Baldissera, E.; Bertolini, G. Takayasu's arteritis: A study of 104 Italian patients. Arthritis Care Res. 2005, 53, 100-107, doi:10.1002/art.20922.

3. Dominguez-Villar, M.; Hafler, D.A. Regulatory T cells in autoimmune disease. Nat. Immunol. 2018, 19, 665-673, doi:10.1038/s41590-018-0120-4.

4. Gao, N.; Cui, W.; Zhao, L.M.; Li, T.T.; Zhang, J.H.; Pan, L.L. Contribution of Th2-like Treg cells to the pathogenesis of Takayasu's arteritis. Clin. Exp. Rheumatol. 2020, 38, 48-54.

5. Wen, D.; Du, X.; Ma, C.S. Takayasu arteritis: Diagnosis, treatment and prognosis. Int. Rev. Immunol. 2012, 31, 462-473, doi:10.3109/08830185.2012.740105.

6. Hoffman, G.S. Treatment of resistant Takayasu's arteritis. Rheum. Dis. Clin. North Am. 1995, 21, 7380.

7. Comarmond, C.; Plaisier, E.; Dahan, K.; Mirault, T.; Emmerich, J.; Amoura, Z.; Cacoub, P.; Saadoun, D. Anti TNF- $\alpha$ in refractory Takayasu's arteritis: cases series and review of the literature. Autoimmun. Rev. 2012, 11, 678-84, doi:10.1016/j.autrev.2011.11.025.

8. Goujon, C.; Bachelez, H. Infliximab. Ann. Dermatol. Venereol. 2019, 146, 483-486, doi:10.1016/j.annder.2019.04.013.

9. Clifford, A.; Hoffman, G.S. Recent advances in the medical management of Takayasu arteritis: an update on use of biologic therapies. Curr. Opin. Rheumatol. 2014, 26, 7-15, doi:10.1097/BOR.0000000000000004.

10. Gribbons, K.B.; Ponte, C.; Carette, S.; Craven, A.; Cuthbertson, D.; Hoffman, G.S.; Khalidi, N.A.; Koening, C.L.; Langford, C.A.; Maksimowicz-McKinnon, K.; et al. Patterns of Arterial Disease in Takayasu Arteritis and Giant Cell Arteritis. Arthritis Care Res. 2020, 72, 1615-1624, doi:10.1002/acr.24055.

11. Tugwell, P.; Boers, M.; Brooks, P.; Simon, L.; Strand, V.; Idzerda, L. OMERACT: An international initiative to improve outcome measurement in rheumatology. Trials 2007, 8, 1-6, doi:10.1186/17456215-8-38.

12. Maffei, S.; Di Renzo, M.; Bova, G.; Auteri, A.; Pasqui, A.L. Takayasu's arteritis: a review of the literature. Intern. Emerg. Med. 2006, 1, 105-112, doi:10.1007/BF02936534.

13. MA Hannawi, S.; Hannawi, H.; Al Salmi, I. Cardiovascular Risk in Rheumatoid Arthritis: Literature Review. Oman Med. J. 2021, 36, e262-e262, doi:10.5001/omj.2021.25.

14. Leone, P.; Cicco, S.; Prete, M.; Solimando, A.G.; Susca, N.; Crudele, L.; Buonavoglia, A.; Colonna, P.; Dammacco, F.; Vacca, A.; et al. Early echocardiographic detection of left ventricular diastolic dysfunction in patients with systemic lupus erythematosus asymptomatic for cardiovascular disease. Clin. Exp. Med. 2020, 20, 11-19, doi:10.1007/s10238-019-00600-8.

15. Hashimoto, Y.; Oniki, T.; Aerbajinai, W.; Numano, F. Aortic regurgitation in patients with Takayasu arteritis: Assessment by color Doppler echocardiography. Heart Vessels 1992, 7, 111-115, 
doi:10.1007/BF01744555.

16. Kong, X.; Ma, L.; Lv, P.; Cui, X.; Chen, R.; Ji, Z.; Chen, H.; Lin, J.; Jiang, L.; Jiang, L. Involvement of the pulmonary arteries in patients with Takayasu arteritis: A prospective study from a single centre in China. Arthritis Res. Ther. 2020, 22, 1-10, doi:10.1186/s13075-020-02203-1.

17. Poels, K.; Neppelenbroek, S.I.M.; Kersten, M.J.; Antoni, M.L.; Lutgens, E.; Seijkens, T.T.P. Immune checkpoint inhibitor treatment and atherosclerotic cardiovascular disease : an emerging clinical problem. 2021, doi:10.1136/jitc-2021-002916.

18. Kim, J.A.; Montagnani, M.; Chandrasekran, S.; Quon, M.J. Role of Lipotoxicity in Endothelial Dysfunction. Heart Fail. Clin. 2012, 8, 589-607, doi:10.1016/j.hfc.2012.06.012.

19. Mozzini, C.; Setti, A.; Cicco, S.; Pagani, M. The most severe paradigm of early cardiovascular disease: Hutchinson-Gilford progeria. Focus on the role of Oxidative Stress. Curr. Probl. Cardiol. 2021, 100900, doi:10.1016/j.cpcardiol.2021.100900.

20. Guo, D.; Zhu, Z.; Zhong, C.; Wang, A.; Xie, X.; Xu, T.; Peng, Y.; Peng, H.; Li, Q.; Ju, Z.; et al. Prognostic Metrics Associated with Inflammation and Atherosclerosis Signaling Evaluate the Burden of Adverse Clinical Outcomes in Ischemic Stroke Patients. Clin. Chem. 2020, 66, 1434-1443, doi:10.1093/clinchem/hvaa201.

21. Everett, B.M.; MacFadyen, J.G.; Thuren, T.; Libby, P.; Glynn, R.J.; Ridker, P.M. Inhibition of Interleukin-1 $\beta$ and Reduction in Atherothrombotic Cardiovascular Events in the CANTOS Trial. J. Am. Coll. Cardiol. 2020, 76, 1660-1670, doi:10.1016/j.jacc.2020.08.011.

22. Liu, C.Y.; Chen, D.; Bluemke, D.A.; Wu, C.O.; Teixido-Tura, G.; Chugh, A.; Vasu, S.; Lima, J.A.C.; Hundley, W.G. Evolution of aortic wall thickness and stiffness with atherosclerosis: Long-term follow up from the multi-ethnic study of atherosclerosis. Hypertension 2015, 65, 1015-1019, doi:10.1161/HYPERTENSIONAHA.114.05080.

23. Jufri, N.F.; Mohamedali, A.; Avolio, A.; Baker, M.S. Mechanical stretch: physiological and pathological implications for human vascular endothelial cells. Vasc. Cell 2015, 7, 8, doi:10.1186/s13221-0150033-z.

24. Sprague, A.H.; Khalil, R.A. Inflammatory cytokines in vascular dysfunction and vascular disease. Biochem. Pharmacol. 2009, 78, 539-552, doi:10.1016/j.bcp.2009.04.029.

25. Williams, B.; Mancia, G.; Spiering, W.; Agabiti Rosei, E.; Azizi, M.; Burnier, M.; Clement, D.L.; Coca, A.; de Simone, G.; Dominiczak, A.; et al. 2018 ESC/ESH Guidelines for the management of arterial hypertension. Eur. Heart J. 2018, 39, 3021-3104, doi:10.1093/eurheartj/ehy339.

26. Georgiopoulos, G.; Tsioufis, C.; Kalos, T.; Magkas, N.; Roussos, D.; Chrysohoou, C.; Sarri, G.; Syrmali, K.; Georgakopoulos, P.; Tousoulis, D. Serum Uric Acid is Independently Associated with Diastolic Dysfunction in Apparently Healthy Subjects with Essential Hypertension. Curr. Vasc. Pharmacol. 2018, 17, 99-106, doi:10.2174/1570161116666171226124959.

27. Ross, I.L.; Marais, A.D. The influence of glucocorticoids on lipid and lipoprotein metabolism and atherosclerosis. South African Med. J. 2014, 104, 671, doi:10.7196/SAMJ.7979.

28. Ben Dhaou, B.; Boussema, F.; Ketari, S.; Cherif, O.; Rokbani, L. HYPERTENSION IN TAKAYASU'S ARTERITIS: PP.38.493. J. Hypertens. 2010, 28, e597, doi:10.1097/01.HJH.0000383830.37815.3C.

29. Benetos, A.; Adamopoulos, C.; Bureau, J.M.; Temmar, M.; Labat, C.; Bean, K.; Thomas, F.; Pannier, B.; Asmar, R.; Zureik, M.; et al. Determinants of accelerated progression of arterial stiffness in normotensive subjects and in treated hypertensive subjects over a 6-year period. Circulation 2002, 
105, 1202-1207, doi:10.1161/hc1002.105135.

30. Franklin, S.S. Arterial stiffness and hypertension: A two-way street? Hypertension 2005, 45, 349351, doi:10.1161/01.HYP.0000157819.31611.87.

31. Mozdzan, M.; Wierzbowska-Drabik, K.; Kurpesa, M.; Trzos, E.; Rechciński, T.; Broncel, M.; Kasprzak, J.D. Echocardiographic indices of left ventricular hypertrophy and diastolic function in hypertensive patients with preserved LVEF classified as dippers and non-dippers. Arch. Med. Sci. 2013, 9, 268275, doi:10.5114/aoms.2013.34534.

32. Catena, C.; Verheyen, N.; Pilz, S.; Kraigher-Krainer, E.; Tomaschitz, A.; Sechi, L.A.; Pieske, B. Plasma Aldosterone and Left Ventricular Diastolic Function in Treatment-Naïve Patients with Hypertension: Tissue-Doppler Imaging Study. Hypertension 2015, 65, 1231-1237, doi:10.1161/HYPERTENSIONAHA.115.05285.

33. Hashimoto, Y.; Oniki, T.; Kaneko, E.; Hata, A.; Matsumura, A.; Kobayashi, T.; Numano, F. Concentric Left Ventricular Hypertrophy in Patients with Takayasu Arteritis. Angiology 1993, 44, 883-888, doi:10.1177/000331979304401106.

34. ROMAN, M.J. Aortic Root Dilatation as a Cause of Isolated, Severe Aortic Regurgitation. Ann. Intern. Med. 1987, 106, 800, doi:10.7326/0003-4819-106-6-800.

35. Lanaspa, M.A.; Rodriguez-Iturbe, B.; Andres-Hernando, A.; Bjornstad, P.; Jensen, T.; Kuwabara, M.; Hara, S.; Nakagawa, T.; Roncal-Jimenez, C.A.; Sato, Y.; et al. Uric Acid Is a Strong Risk Marker for Developing Hypertension From Prehypertension. Hypertension 2017, 71, 78-86, doi:10.1161/hypertensionaha.117.10370.

36. Kuwabara, M.; Borghi, C.; Cicero, A.F.G.; Hisatome, I.; Niwa, K.; Ohno, M.; Johnson, R.J.; Lanaspa, M.A. Elevated serum uric acid increases risks for developing high LDL cholesterol and hypertriglyceridemia: A five-year cohort study in Japan. Int. J. Cardiol. 2018, 261, 183-188, doi:10.1016/j.ijcard.2018.03.045.

37. Catena, C.; Colussi, G.; Capobianco, F.; Brosolo, G.; Sechi, L.A. Uricaemia and left ventricular mass in hypertensive patients. Eur. J. Clin. Invest. 2014, 44, 972-981, doi:10.1111/eci.12331.

38. Culleton, B.F.; Larson, M.G.; Kannel, W.B.; Levy, D. Serum Uric Acid and Risk for Cardiovascular Disease and Death: The Framingham Heart Study. Ann. Intern. Med. 1999, 131, 7, doi:10.7326/00034819-131-1-199907060-00003.

39. Liu, T.; Zhang, L.; Joo, D.; Sun, S.C. NF-KB signaling in inflammation. Signal Transduct. Target. Ther. 2017, 2, doi:10.1038/sigtrans.2017.23.

40. Netea, M.G.; Kullberg, B.J.; Blok, W.L.; Netea, R.T.; Van Der Meer, J.W.M. The role of hyperuricemia in the increased cytokine production after lipopolysaccharide challenge in neutropenic mice. Blood 1997, 89, 577-582, doi:10.1182/blood.v89.2.577.

41. Kang, D.H.; Park, S.K.; Lee, I.K.; Johnson, R.J. Uric acid-induced C-reactive protein expression: Implication on cell proliferation and nitric oxide production of human vascular cells. J. Am. Soc. Nephrol. 2005, 16, 3553-3562, doi:10.1681/ASN.2005050572.

42. Park, S.; Lakatta, E.G. Role of inflammation in the pathogenesis of arterial stiffness. Yonsei Med. J. 2012, 53, 258-261, doi:10.3349/ymj.2012.53.2.258.

43. Patterson, R.A.; Horsley, E.T.M.; Leake, D.S. Prooxidant and antioxidant properties of human serum ultrafiltrates toward LDL: Important role of uric acid. J. Lipid Res. 2003, 44, 512-521, doi:10.1194/jlr.M200407-JLR200. 
44. Choi, Y.J.; Yoon, Y.; Lee, K.Y.; Hien, T.T.; Kang, K.W.; Kim, K.C.; Lee, J.; Lee, M.Y.; Lee, S.M.; Kang, D.H.; et al. Uric acid induces endothelial dysfunction by vascular insulin resistance associated with the impairment of nitric oxide synthesis. FASEB J. 2014, 28, 3197-3204, doi:10.1096/fj.13-247148.

45. Zharikov, S.; Krotova, K.; Hu, H.; Baylis, C.; Johnson, R.J.; Block, E.R.; Patel, J. Uric acid decreases NO production and increases arginase activity in cultured pulmonary artery endothelial cells. Am. J. Physiol. - Cell Physiol. 2008, 295, 1183-1190, doi:10.1152/ajpcell.00075.2008.

46. Jin, M.; Yang, F.; Yang, I.; Yin, Y.; Luo, J.J.; Wang, H.; Yang, X.F. Uric acid, hyperuricemia and vascular diseases. Front. Biosci. 2012, 17, 656-669, doi:10.2741/3950.

47. Suzuki, T. Nitrosation of uric acid induced by nitric oxide under aerobic conditions. Nitric Oxide - Biol. Chem. 2007, 16, 266-273, doi:10.1016/j.niox.2006.10.008.

48. Corry, D.B.; Eslami, P.; Yamamoto, K.; Nyby, M.D.; Makino, H.; Tuck, M.L. Uric acid stimulates vascular smooth muscle cell proliferation and oxidative stress via the vascular renin-angiotensin system. J. Hypertens. 2008, 26, 269-275, doi:10.1097/HJH.0b013e3282f240bf.

49. Patel, D.A.; Lavie, C.J.; Milani, R. V.; Shah, S.; Gilliland, Y. Clinical implications of left atrial enlargement: A review. Ochsner J. 2009, 9, 191-196, doi:10.1043/1524-5012-9.4.191.

50. Cangemi, R.; Calvieri, C.; Taliani, G.; Pignatelli, P.; Morelli, S.; Falcone, M.; Pastori, D.; Violi, F. Left Atrium Dilatation and Left Ventricular Hypertrophy Predispose to Atrial Fibrillation in Patients With Community-Acquired Pneumonia. Am. J. Cardiol. 2019, 124, 723-728, doi:10.1016/j.amjcard.2019.05.051.

51. Yin, Y.; Zhang, Y.; Wang, D.; Han, X.; Chu, X.; Shen, M.; Zeng, X. Complete blood count reflecting the disease status of giant cell arteritis: A retrospective study of Chinese patients. Medicine (Baltimore). 2020, 99, e22406, doi:10.1097/MD.0000000000022406.

52. MACCHIONI, P.; BOIARDI, L.; SALVARANI, C.; ROSS, F.; CASADEI-MALDINI, M.; MANCINI, R.; BELTRANDI, E.; PORTIOLI, I. LYMPHOCYTE SUBPOPULATIONS ANALYSIS IN PERIPHERAL BLOOD IN POLYMYALGIA RHEUMATICA/GLANT CELL ARTERITIS. Rheumatology 1993, 32, 666-670, doi:10.1093/RHEUMATOLOGY/32.8.666.

53. Weyand, C.M.; Goronzy, J.J. Medium- and Large-Vessel Vasculitis. http://dx.doi.org/10.1056/NEJMra022694 2009, 349, 160-169, doi:10.1056/NEJMRA022694.

54. Bianchi, M.E.; Manfredi, A.A. High-mobility group box 1 (HMGB1) protein at the crossroads between innate and adaptive immunity. Immunol. Rev. 2007, 220, 35-46, doi:10.1111/J.1600065X.2007.00574.X.

55. Cicco, S.; Cicco, G.; Racanelli, V.; Vacca, A. Neutrophil Extracellular Traps (NETs) and DamageAssociated Molecular Patterns (DAMPs): Two Potential Targets for COVID-19 Treatment. Mediators Inflamm. 2020, 2020, 1-25, doi:10.1155/2020/7527953.

56. Song, H.; Feng, Y.; Hoeger, S.; Beck, G.; Hanusch, C.; Goettmann, U.; Leuvenink, H.G.D.; Ploeg, R.J.; Hillebrands, J.; Yard, B.A. High mobility group box 1 and adenosine are both released by endothelial cells during hypothermic preservation. Clin. Exp. Immunol. 2008, 152, 311-319, doi:10.1111/j.13652249.2008.03643.x.

57. Chavakis, E.; Hain, A.; Vinci, M.; Carmona, G.; Bianchi, M.E.; Vajkoczy, P.; Zeiher, A.M.; Chavakis, T.; Dimmeler, S. High-mobility group box 1 activates integrin-dependent homing of endothelial progenitor cells. Circ. Res. 2007, 100, 204-212, doi:10.1161/01.RES.0000257774.55970.f4.

58. Palumbo, R.; Galvez, B.G.; Pusterla, T.; De Marchis, F.; Cossu, G.; Marcu, K.B.; Bianchi, M.E. Cells 
migrating to sites of tissue damage in response to the danger signal HMGB1 require NF-KB activation. J. Cell Biol. 2007, 179, 33-40, doi:10.1083/jcb.200704015.

59. Salvarani, C.; Cantini, F.; Hunder, G.G. Polymyalgia rheumatica and giant-cell arteritis. Lancet 2008, 372, 234-245, doi:10.1016/S0140-6736(08)61077-6.

60. Dumitriu, I.E.; Baruah, P.; Bianchi, M.E.; Manfredi, A.A.; Rovere-Querini, P. Requirement of HMGB1 and RAGE for the maturation of human plasmacytoid dendritic cells. Eur. J. Immunol. 2005, 35, 2184-2190, doi:10.1002/eji.200526066.

61. Maugeri, N.; Rovere-Querini, P.; Baldini, M.; Sabbadini, M.G.; Manfredi, A.A. Translational MiniReview Series on Immunology of Vascular Disease: Mechanisms of vascular inflammation and remodelling in systemic vasculitis. Clin. Exp. Immunol. 2009, 156, 395-404, doi:10.1111/j.13652249.2009.03921.x.

62. Hellmich, B.; Agueda, A.; Monti, S.; Buttgereit, F.; De Boysson, H.; Brouwer, E.; Cassie, R.; Cid, M.C.; Dasgupta, B.; Dejaco, C.; et al. 2018 Update of the EULAR recommendations for the management of large vessel vasculitis. Ann. Rheum. Dis. 2020, 79, 19-130, doi:10.1136/annrheumdis-2019-215672.

63. Lloyd-Jones, D.M.; Huffman, M.D.; Karmali, K.N.; Sanghavi, D.M.; Wright, J.S.; Pelser, C.; Gulati, M.; Masoudi, F.A.; Goff, D.C. Estimating Longitudinal Risks and Benefits From Cardiovascular Preventive Therapies Among Medicare Patients. J. Am. Coll. Cardiol. 2017, 69, 1617-1636, doi:10.1016/j.jacc.2016.10.018.

64. Cicco, S.; Calvanese, C.; Susca, N.; Inglese, G.; Nardiello, E.; Ciampi, S.; Tedesco, P.A.; Cirulli, A.; Panettieri, I.; Vacca, A.; et al. Right atrium enlargement is related to increased heart damage and mortality in well-controlled hypertension. Nutr. Metab. Cardiovasc. Dis. 2021, 0 , doi:10.1016/J.NUMECD.2021.10.004.

65. Cicco, S.; Solimando, A.G.; Buono, R.; Susca, N.; Inglese, G.; Melaccio, A.; Prete, M.; Ria, R.; Racanelli, V.; Vacca, A. Right Heart Changes Impact on Clinical Phenotype of Amyloid Cardiac Involvement: A Single Centre Study. Life 2020, 10, 247, doi:10.3390/life10100247.

66. Lang, R.M.; Badano, L.P.; Mor-Avi, V.; Afilalo, J.; Armstrong, A.; Ernande, L.; Flachskampf, F.A.; Foster, E.; Goldstein, S.A.; Kuznetsova, T.; et al. Recommendations for cardiac chamber quantification by echocardiography in adults: An update from the American society of echocardiography and the European association of cardiovascular imaging. Eur. Heart J. Cardiovasc. Imaging 2015, 16, 233-271, doi:10.1093/ehjci/jev014.

67. Stefanadis C, Stratos C, Boudoulas H, Kourouklis C, T.P. Distensibility of the ascending aorta: comparison of invasive and non-invasive techniques in healthy men and in men with coronary arterydisease. Eur Hear. 1990, 990-996.

68. Ferguson, G.G.; Eliasziw, M.; Barr, H.W.K.; Clagett, G.P.; Barnes, R.W.; Wallace, M.C.; Taylor, D.W.; Haynes, R.B.; Finan, J.W.; Hachinski, V.C.; et al. The North American Symptomatic Carotid Endarterectomy Trial. Stroke 1999, 30, 1751-1758, doi:10.1161/01.STR.30.9.1751. 